\title{
Från Forneby till Gamla Uppsala - några nyheter om runristaren Erik
}

\section{Magnus Källström}

I Per Stilles avhandling Runstenar och runristare $i$ det vikingatida Fjädrundaland (1999) spelar runristaren Erik en viktig roll. Han tillhör tillsammans med Balle, Livsten och Tidkume de mest produktiva runristarna i denna del av Uppland och har enligt Stilles bedömning utfört sammanlagt 20 i dag kända ristningar, varav inte mindre än 18 finns inom det aktuella området. ${ }^{1}$ Till skillnad mot de övriga tre verkar han dock inte ha velat skylta med sitt namn. Endast en av stenarna - U 1165 Rotbrunna i Härnevi socken - är signerad och då märkligt nog i lönnskrift.

Trots att Eriks produktion är ganska stor tillhör han inte de mer namnkunniga bland de uppländska runristarna. En anledning är säkert att hans ristningar är mycket homogena och att texterna är enkla och relativt korta. Ristningarna har alltid samma uppläggning: en enkel slinga som nedtill hålls ihop av en palmettförsedd bandknut. Rundjurets huvud är genomgående avbildat i fågelperspektiv och mycket snarlika kors återkommer i ristning efter ristning. De senare har alltid en smalare fot, som utgår från bandknuten. Erik har också flera karakteristiska runformer som t.ex. den smala s-runan och en ovanligt konsekvent ortografi. Att avgöra vilka ristningar som skall attribueras till denne ristare är därför inte särskilt komplicerat och de flesta av dem sammanfördes redan av Erik

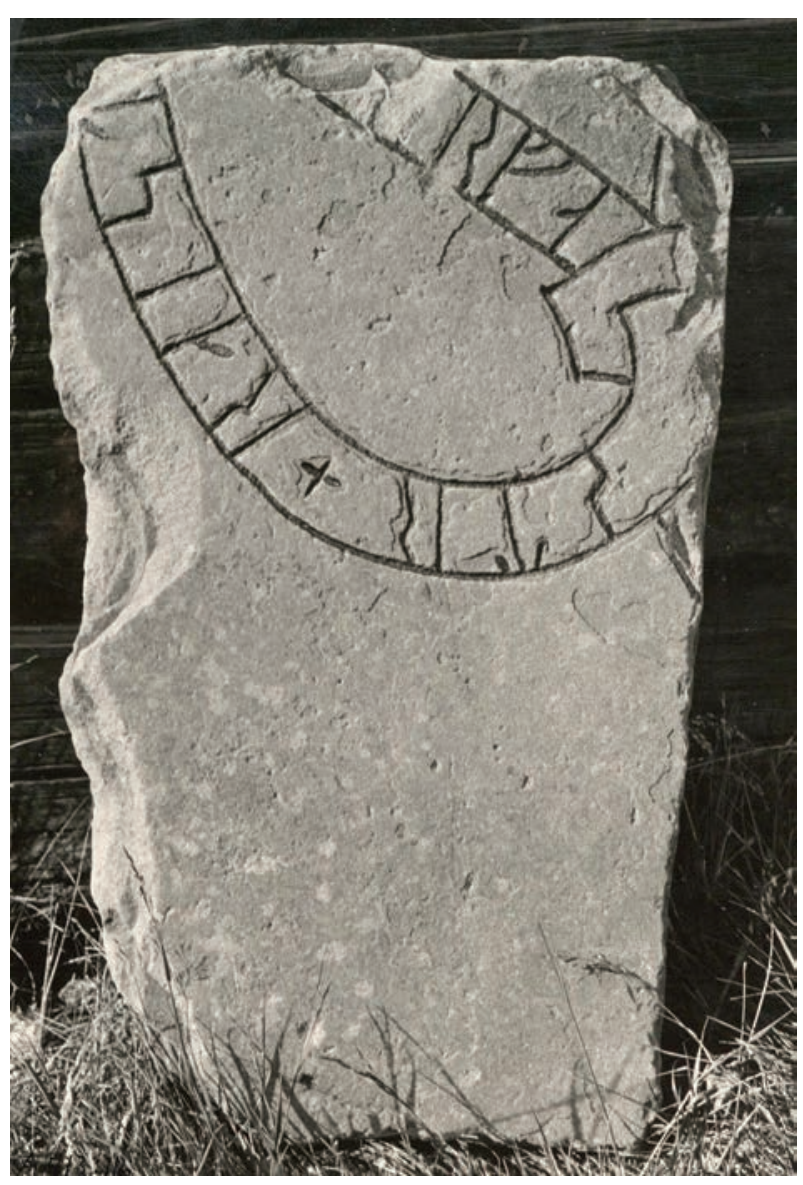

Fig. 1. Runstenen Vs 30 från Forneby, Möklinta socken, Västmanland. Foto Nils Lagergren (ATA). Brate i Svenska runristare (1925). ${ }^{2}$ Trots detta har Stille i sin avhandling lyckats utöka samlingen, bl.a. genom att i en fotnot peka på att runstenen Vs 30 vid Forneby i Möklinta socken i Västmanland (fig. 1) måste vara

\footnotetext{
1 Stille 1999, s. 204

2 Brate 1925, s. 63 ff. - En översiktlig genomgång av Eriks ristningar finns även hos Quak 2003, som dock inte har tagit hänsyn till Stilles arbete.
} 
utförd av just denne ristare. ${ }^{3}$ Stille ger inga argument för sin attribution mer än att stenen uppvisar likheter med Eriks ristningar, men det råder ingen tvekan om att han har rätt.

Egentligen borde inte utgångspunkten för en attribuering vara särskilt gynnsam i detta fall, eftersom Fornebystenen utgörs av ett fragment med endast ett brottstycke av texten: ...-rfastr + raist... [Do]rfastr rœeist [i]... »Torfast reste ...». Tittar man närmare på inskriften noterar man dock flera för Erik typiska runformer. Runan a har exem-

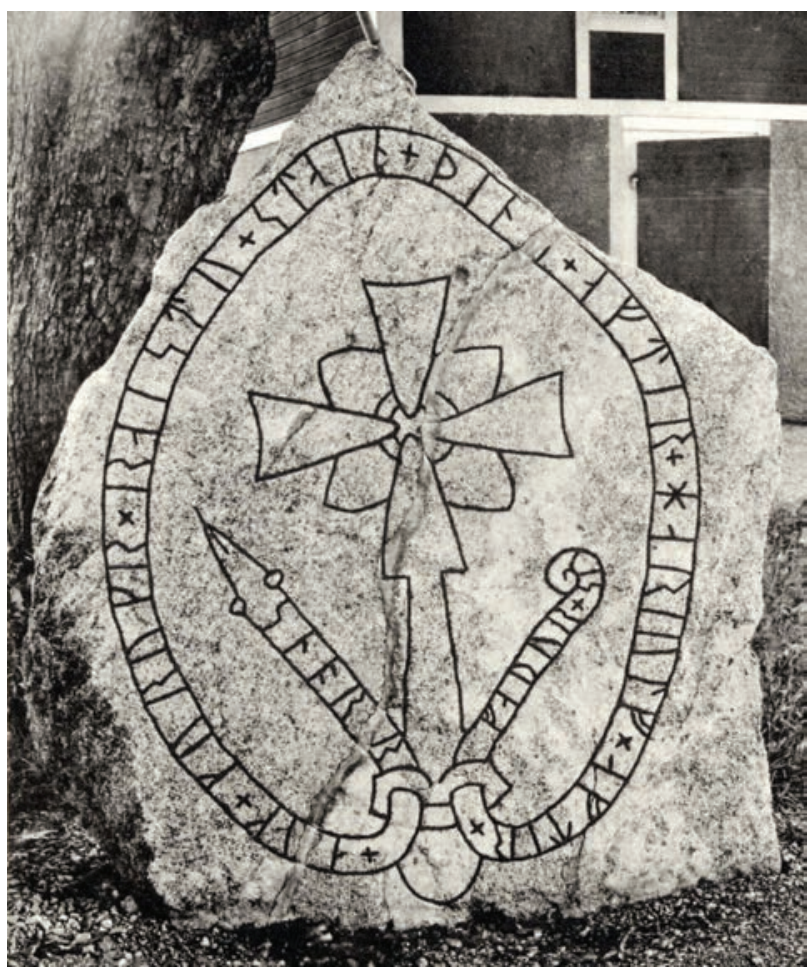

Fig. 2. Runstenen U 1156 från Hjälteberga i Simtuna socken, Uppland. Efter Upplands runinskrifter. pelvis bara bistav till vänster om huvudstaven och den första av s-runorna är mycket smal och har dessutom en för Erik mycket karakteristisk bakvänd form med sluttande mellanled. ${ }^{4}$ Skiljetecknet är korsformigt (+), något som är mycket vanligt i Eriks ristningar. Det som kan sägas om ortografin talar inte heller emot den föreslagna attribueringen. Diftongen /æi/ återges med ai, vilket är det vanliga hos Erik. ${ }^{5}$ Den defekta runan i början av inskriften har troligen varit $\mathbf{u}$, vilket betyder att förleden i namnet bör ha haft formen pur. Erik använder alltid $\mathbf{u}$ för att beteckna /o(:)/, medan o-runan - som Stille också har visat - verkar ha reserverats för nasalt /a/ och /æ/. ${ }^{6}$ Även om mycket lite återstår av ornamentiken går det att se att den har anslutit till utformningen på de övriga stenarna. De båda slingändarna har nedtill varit sammanhållna med en elegant bandknut med en nedåtriktad palmett. Bandknuten har svagt konkava sidor och har förmodligen sett ut exakt som på U 1156, den sten som Stille har valt att reproducera som ett typiskt exempel på Eriks ristningskonst (fig. 2). ${ }^{7}$ Fornebystenen har också haft ett kors, men av detta ser man på det aktuella fragmentet bara en kort vertikal linje tillhörande foten.

I detta sammanhang måste nämnas att det numera finns ytterligare ett fragment av Fornebystenen utöver det som är beskrivet i Västmanlands runinskrifter. Det blev först känt vid fornminnesinventeringen 1989, men har inte blivit publicerat. Fragmentet förvaras liksom den tidigare kända delen av stenen vid Möklinta Gammelgård. Om nyfyndet har Fornminnesregistret följande uppgifter: »Stenen har skänkts till Gammelgården av Knut Åberg som hittat fragmentet i sin loge i Forneby. K. Åberg vet ej var den ursprungligen

3 Stille 1999, s. 160 not 7.

4 Se vidare Stille 1999, s. 160.

5 Stille 1999, s. 205, Quak 2003, s. 655.

6 Stille 1999, s. 205, jfr Quak 2003, s. 654.

7 Stille 1999, s. 161. 
kommer från. ${ }^{8}$ Det nyfunna fragmentet (fig. 3) mäter $21 \times 28 \mathrm{~cm}$ och består också av röd sandsten. Redan vid fornminnesinventeringen konstaterade man att det måste ha tillhört samma sten som Vs 30, vilket utan tvivel är riktigt. Såväl tjockleken $(10-11 \mathrm{~cm})$ som den strimmiga struktur som sandstenen har i brottytorna överensstämmer.

På ena sidan av det nyfunna fragmentet finns en modern ristning med versaler som lyder »LEIF GJORDE STENEN TILL MINNE AV» följt av något oläsligt som verkar börja på $\mathrm{T}$, medan den andra sidan upptas av delar av ett kors i typisk runstensstil. Denna ristning gör ett genuint intryck och korset överensstämmer i detalj med en av de korstyper som brukar förekomma på Eriks stenar. Korset på det mindre fragmentet ger alltså ytterligare stöd åt att Stilles attribuering är riktig.

Runstenen vid Forneby har varit känd länge. Den omtalas redan i Rannsakningarna 1667 och hade då sin plats på åsen vid Forneby. Av en senare inkommen relation från perioden 1682-83 framgår att det intill stenen också skall ha funnits någon form av forntida gravar. Det talas här om »små plattzer medh Steen anlagde och något lijtet förhögde [...] som skulle i gambla tijderne warit graafplattzer». ${ }^{9}$ Vid grävningar på åsen år 1844 påträffades också en vapenutrustning bestående av

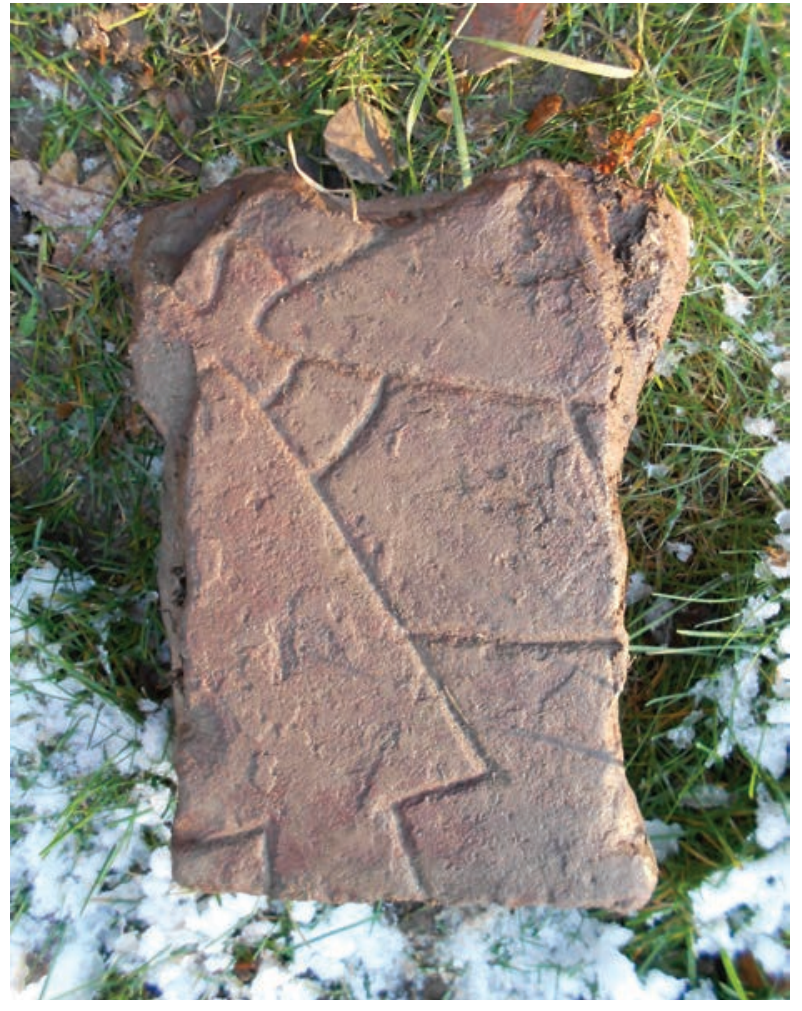

Fig. 3. Det nyfunna fragmentet av Vs 30. Foto förf. bland annat svärd, lans, sköldbuckla, yxa, pilspetsar och ett hästbetsel. ${ }^{10}$ De märkliga fynden antas ha tillhört en förstörd ryttargrav och enligt den skrivelse som inkom till Vitterhetsakademien samma år skulle de ha gjorts »i granskapet af en Runsten, hvilken funnits på åsen vid Forneby, men vid en Byen år 1810 öfvergången brand förstörts». Att stenen skulle ha förstörts av brand är dock knappast riktigt, eftersom de mått som anges i Rannsakningarna stämmer väl överens med de måttuppgifter som Herman Hofberg meddelar 1873. ${ }^{11}$ Däremot är det av visst intresse att Olof Grau 1754 uppger att stenen var sönderslagen i tre delar, även om han i ett tillägg i slutet av boken nämner att två av dessa »finnas nu ej igen». ${ }^{12}$ Detta tyder på att det vid någon tidpunkt funnits flera fragment av stenen på åsen och det är inte osannolikt att det nyfunna fragmentet har varit ett av dessa. Om den plats för vapenfynden som anges i Fornminnesregistret är korrekt

8 Raä Möklinta 4:2.

9 Rannsakn. 1, s. 137

10 Raä Möklinta 8:1, SHM inv. nr 1111.

11 Se referat i VsR s. 89.

12 Grau 1754, s. 575 samt på den opaginerade sistasidan. 
betyder det också att runstenen ursprungligen har stått närmare 300 meter sydväst om den markering för stenens tidigare placering som finns i registret. ${ }^{13}$

Redan uppgifterna i Rannsakningarna visar att ryttargraven inte kan ha legat ensam utan att det funnits flera gravar på platsen. Grau nämner att det $\mathrm{i}$ åsen framkommit »Pilar [...] fundne i krukor» och Richard Dybeck har 1868 uppgifter om »stensättningar vid Fornby». ${ }^{14}$ Så sent som 1945 inrapporterades till Riksantikvarieämbetet att »urnor påträffats vid grävning för stolpar efter en väg i Forneby», men det är oklart om någon närmare undersökning kom till stånd. ${ }^{15}$

Att det legat en påkostad ryttargrav intill runstenen kan vara mer än en tillfällighet. Svärdet som ingår i vapenutrustningen tillhör nämligen Petersens typ Z, en variant som dyker upp sent i det vikingatida materialet. Enligt Fedir Androshchuk saknas denna typ av svärd i gravarna i Birka, men finns representerad i stadslager från Lund och Sigtuna. Han daterar den därför till 1000-talet första hälft. ${ }^{16}$ Detta överensstämmer väl med dateringen av den djurornamentik som Erik använder. Enligt Anne-Sofie Gräslunds bekanta typologi ska runstenar med rundjuret avbildat i fågelperspektiv nämligen föras till perioden ca 1010-50 (se t.ex. Gräslund 2006 s. 126 f.). Det är alltså fullt möjligt att det funnits ett nära samband mellan runstenen på Fornbyåsen och den märkliga gravläggningen.

Både gravfältet med ryttargraven och runstenen vid Forneby har uppenbarligen varit belägna på en väl utvald plats intill en vägsträckning, som har följt åssystemen från Västeråstrakten och vidare norrut till södra Dalarna. I Möklinta går vägen längs den östra stranden av Storsjön och passerar sedan förbi Möklinta kyrka, som ligger ett par kilometer norr om Forneby. Att denna väg varit av stor betydelse framgår inte minst av beskrivningen hos Grau: ${ }^{17}$

Kyrkan står på Krono-grund uppå en hög sandås, som är en och samma ås, hwilken sträcker sig igenom Balunda och Romfärtuna socknar neder i landet, [...] och här ifrån Kyrkan går han widare fram igenom socknen i norr up åt älfwen och så fram åt By sockns Kyrka i Kopparbärgs Höfdingedöme på andra sidan om älfwen. På denna ås, här kallad Fornby-åsen, äro månge gamle Begrafnings-platser.

I sina tillägg och rättelser i slutet av boken tillfogar han dessutom om Forneby: »Här i byn är Gästgifwaregård på stora Landsvägen, som sträcker sig utur Wästmanland in i Kopparbärgs Höfdingedöme igenom By sockn.»

Samtliga stenar som har tillskrivits ristaren Erik är av granit, men för stenen vid Forneby har han valt ett avvikande stenmaterial. Röd sandsten associeras i Uppland ofta med det yngsta skiktet av runstenar, som uppträder i anslutning till många medeltida

13 Raä Möklinta 8:1 resp. 33:1.

14 Grau 1754 på den opaginerade sistasidan; Dybeck 1868, s. 28.

15 ATA dnr 4937/45.

16 Androshchuk 2014, s. 166, 170, 172.

17 Grau 1754 s. 572. 
kyrkplatser och som brukar dateras till slutet av 1000-talet eller början av 1100-talet. ${ }^{18}$ Fornebystenen avviker här, dels för att ristaren Erik av allt att döma var verksam under 1000-talets första hälft, dels för att den inte alls tycks ha haft anknytning till någon medeltida kyrka. ${ }^{19}$ Visserligen finns vid samma väg en halvkilometer längre söderut en plats med namnet Kapellbacken och en tradition om ett bönekapell eller mindre kyrka, men det är tveksamt om uppgiften ska tillmätas någon betydelse i detta sammanhang. ${ }^{20}$

Fornebystenen är faktiskt inte det enda exemplet på att Erik har arbetat i sandsten utan han har av allt att döma använt detta material i ytterligare två runstenar, vilket inte tidigare verkar ha uppmärksammats i tryck. ${ }^{21}$ Förmodligen beror det på att de varken finns i Fjädrundaland eller i Västmanland utan i hjärtat av det gamla Tiundaland. Den ena (U 943) står i dag rest i Universitetsparken bakom Gustavianum (fig. 4), medan den andra (U 978) sitter inmurad i absiden till Gamla Uppsala kyrka (fig. 5). U 943 påträffades troligen på 1910talet vid renoveringen av Ärkebiskopsgården i Uppsala, medan U 978 tidigare låg som altarskiva inne i kyrkan. ${ }^{22}$

Den som ser dessa stenar tillsammans kan knappast tveka om att de måste vara utförda av samma person. Förmodligen har redan Elias Wessén varit inne på detta. Han beskriver nämligen dem på ett likartat sätt och betonar i båda fallen den dominerande ställning som korset intar på ristningsytan.

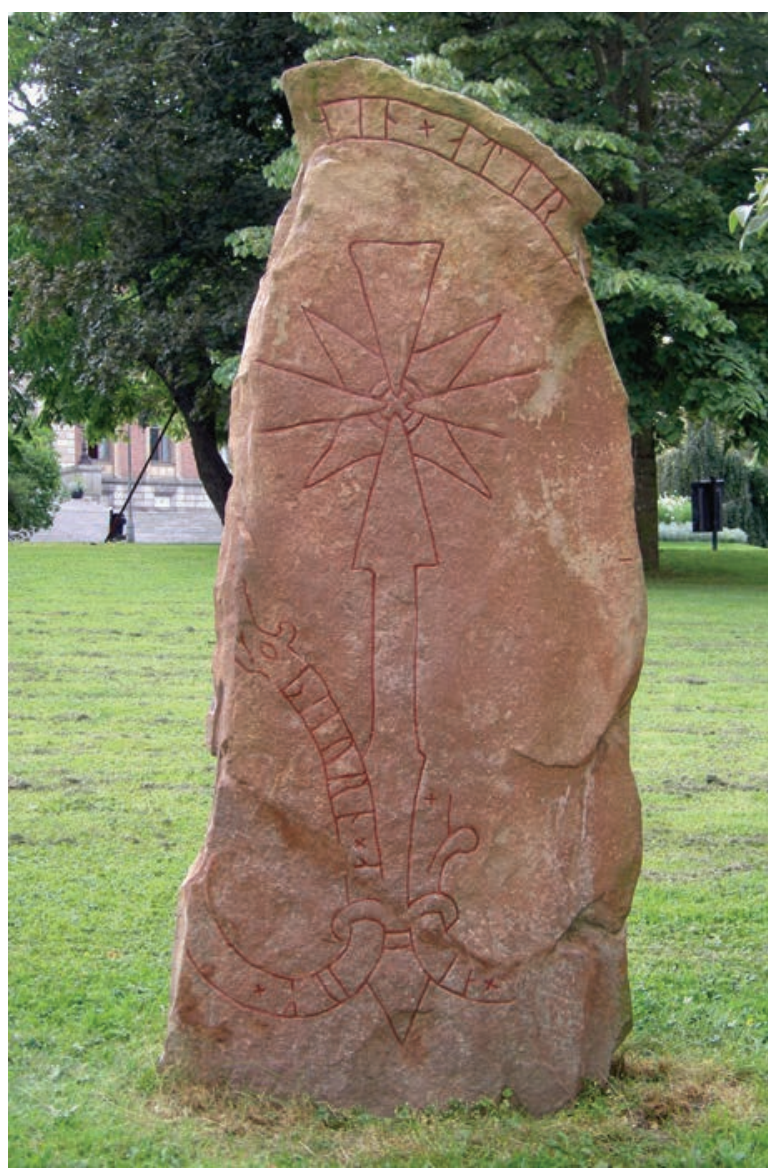

Fig. 4. Runstenen U 943 från Ärkebiskopsgården i Uppsala. Foto förf. Han framhåller att detta tillsammans med valet av stenmaterial talar för att U 943 »från början har varit rest på en kristen begravningsplats, sannolikt inom det nuvarande Uppsalas område» och att U 978 kan ha haft en motsvarande placering i Gamla Uppsala (»på en kristen kyrkogård»). ${ }^{23}$

\footnotetext{
18 Hagenfeldt \& Palm 1996, s. 60 ff.

19 Angående dateringen se diskussion hos Stille 1999, s. 206, 211.

20 Se Raä Möklinta 128:1.

21 Jfr dock mitt meddelande i Zachrisson 2013, s. 177. - I samband med det 24:e internationella fältrunologmötet i Uppsala den 23-25 september 2011 visade prof. Henrik Williams runstenarna i Universitetsparken och framför U 943 ställde han frågan vem som hade ristat stenen. Per och jag var inte i samma grupp och hade aldrig diskuterat denna sak, men enligt Williams gav vi båda samma svar: Erik.

22 UR 4, s. 46 resp. $126 \mathrm{f}$.

23 UR 4, s. 47 resp. 129.
} 
Märkligare är kanske att ingen mig veterligt (jfr dock not 21 ovan) har associerat dessa stenar med ristaren Erik. Visserligen är inte rundjurshuvudena avbildade i fågelperspektiv som man normalt finner hos denne ristare, men i stort sett alla övriga för honom typiska drag finns där. Detta blir helt uppenbart om man går igenom de olika detaljerna.

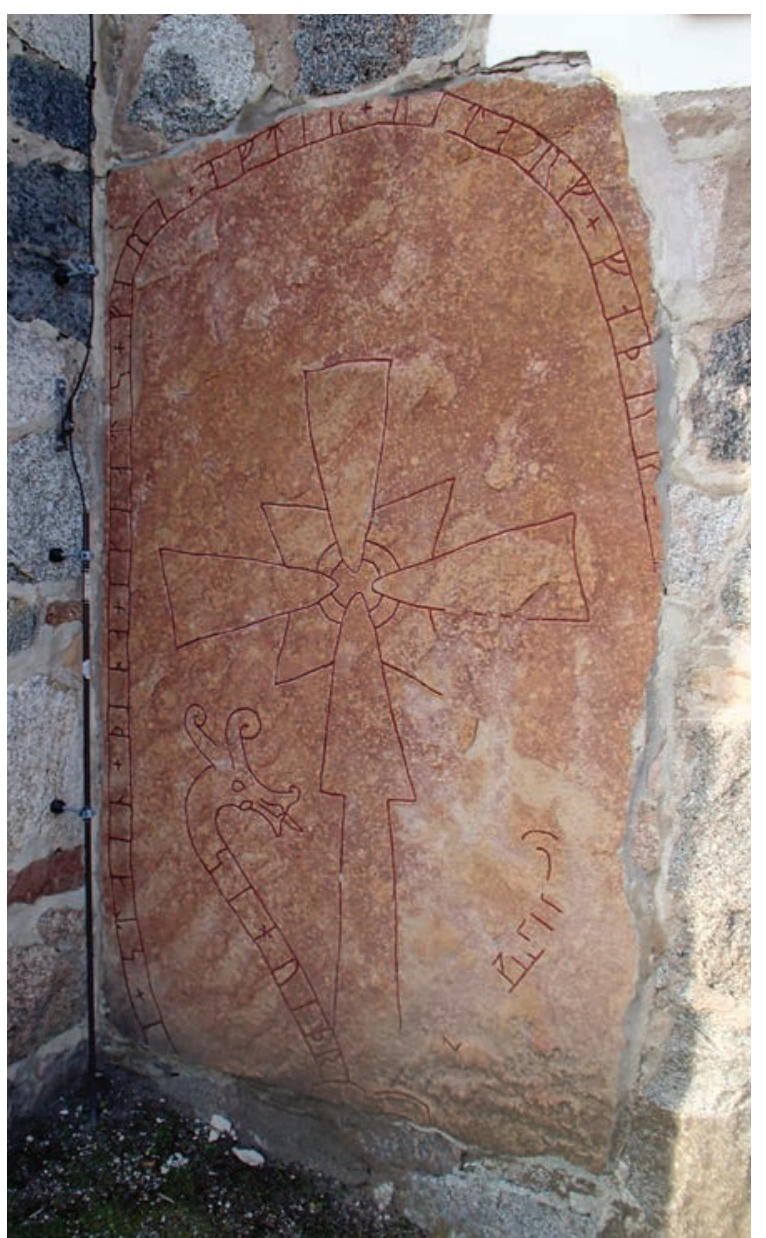

Fig. 5. Runstenen U 978 i Gamla Uppsala kyrka. Foto förf. Inskrifterna på de båda stenarna återges på följande sätt i Sveriges runinskrifter: ${ }^{24}$

U 943:

biaurn $\times$ auk $\times \ldots$ ain $\times$ atir $\times-[k a] \ldots$ ant $+$

Biorn ok ... [st] æin ceftiR ... and.

»Björn och ... stenen efter ... ande.»

U 978:

sihuipr ... -i + stain + pina + iklats + fari + iftir + uitarf + fap(u)(r) [+ - ... sia $]$... ku--Sigviðr [ræist]i stcein penna Anglandsfari ceftiR Vidiarf, faður ...

»Sigvid Englandsfararen reste denna sten efter Vidjärv, [sin] fader ...»

Båda stenarna är som nämnts av röd sandsten och de påminner om varandra till form och storlek. Ristningarna domineras också av ett centralt placerat kors med en smalare fot, som är av exakt den typ som brukar förekomma hos Erik. På U 978 har rundjurshuvudet fått en mycket originell utformning med konkav nos och två uppåtstående nackflikar som är sammanrullade i ändarna. Huvudet på U 943 är något skadat, men har uppenbarligen varit av en något enklare typ. Det går dock även att i dessa ristningar se släktskap med rundjurshuvudena på Eriks övriga ristningar genom de spetsovala eller rombiska ögonen, som har direkta motsvarigheter på flera av hans stenar (t.ex. U 779, U 1155, U 1172).

Runformerna stämmer fullständigt med Eriks övriga ristningar. Exempelvis har n- och a-runorna ensidiga bistavar och skiljetecknen är i regel korsformiga. Runan b på U 943 har öppen form, vilket är den variant som b-runan som normalt förekommer hos Erik (t.ex. på U 738, U 755, U 1173). Även ortografiskt finns flera överensstämmelser som att r står för äldre /R/ (atir U 943 resp. iftir U 978 för ceftiR) och att h-runan används för frikativt /g/ (sihuipr U 978). ${ }^{25}$ Skrivningen iftir på U 978 med en inledande i-runa kan (trots det osäkra belägget [iftir] på den försvunna U 798†) kan verka främmande, efter-

24 UR 4, s. 47 resp. 127.

25 Stille 1999, s. 206, Quak 2003, s. 654, 655. 
som Erik annars nästan alltid använder skrivningen aftir. ${ }^{26}$ En närmare granskning visar dock att denna form också finns på stenen i Gamla Uppsala. Den inledande runan har nämligen lästs som a i samtliga äldre källor (Peringskiöld, Celsius, Dybeck, v. Friesen) ${ }^{27}$ och är nu även uppmålad så på stenen. Vad jag har kunnat finna är denna bistav också ristad (senast kontrollerat den 9 mars 2014), vilket betyder att läsningen i Upplands runinskrifter är felaktig på denna punkt.

Mycket originell är skrivningen biaurn på U 943, där det ser ut som om ristaren har bemödat sig att spegla det å-haltiga uttal som den senare komponenten i diftongen bör ha haft (motsvarande fvn. [o]). Exakt samma skrivning biaurn för Bi[o]rn finns på en annan av Eriks stenar (U 768) och dessa två är faktiskt de enda förekomsterna av denna skrivning i hela det uppländska runmaterialet (Namnleden bi[o]rn förekommer däremot ytterligare fem gånger i Eriks ristningar, men återges då med den mer frekventa skrivningen biarn). ${ }^{28}$

Om inskrifternas formulering finns mindre att säga, men det kan nämnas att U 978 måste ha haft ett verb i preteritum (troligen ræisti), vilket är den form som Erik genomgående använder (aldrig let( $u$ ) rceisa). Typisk är också att det demonstrativa pronomenet i sg. ack. m. uppträder i formen penna. På U 943 står objektet stcin däremot utan pronomen, vilket dock även har paralleller på ett fåtal av Eriks stenar (U 798†, U 1155, U 1173).

Jag tror följaktligen att vi med fullständig säkerhet kan räkna U 943 och U 978 till ristaren Erik, vilket betyder att hans samlade produktion numera uppgår till 22 kända stenar. De två nytillkomna stenarna har båda förts till stilgruppen Pr 2, som Gräslund (2006 s. 126) daterar till perioden ca 1020-50, alltså ungefär samma tidsavsnitt som ristningar med rundjurshuvud i fågelperspektiv.

Som nämnts är Eriks ristningar mycket snarlika och i stort sett samma motiv går igen på sten efter sten. Stille har dock påpekat att det finns vissa skillnader i utformningen av korsflikarna och palmettfliken i bandknuten, där »mer rundade former [...] varierar med spetsiga». ${ }^{29}$ Han menar att materialet utifrån detta kan delas i tre grupper: en med rundade former, en mellangrupp och en med spetsiga former, och att det kanske rör sig om »en intern stilutveckling hos Erik» där »de ristningar som har rundade former är äldre än de med spetsiga».

Jag är övertygad om att Stille här har gjort en mycket viktig iakttagelse. För det mesta går nämligen de två formelementen hand i hand, dvs. en sten som bär ett kors med rundade korsflikar har också en palmett med rundad form (t.ex. U 768, U 774, U 1165), medan spetsiga korsflikar åtföljs av en palmett som upprepar samma spetsiga form (t.ex. U 779, U 1155, U 1173). Det finns dock ett par exempel som kombinerar (relativt) spetsiga korsflikar med rundade palmetter (U 1154, U 1157) och båda dessa stenar placerar Stille i gruppen med »mellanformer», vilket också är det förväntade om man tänker sig

26 Stille 1999, s. 160, Quak 2003, s. 655.

27 Se referat i UR 4, s. 128.

28 Se även Quak 2003, s. 655.

29 Stille 1999, s. 205. 
en successiv utveckling. Samtidigt tror jag att denna mellangrupp egentligen kan delas i två: en med bladlika flikar och en med breda spetsiga flikar. Även om övergångarna givetvis är flytande skulle jag vilja dela upp Eriks ristningar i följande fyra grupper, som kan uppfattas som en kronologisk sekvens: (1) U 774, U 768, U 1165, U 738; (2) U 1156, U 769, U 793, U 1157; (3) U 1154, U 978, U 732, U 857, U 762, U 779, U 755, Vs 30; (4) U 1153†, U 798†, U 1155, U 1173, U 1172, U 943. ${ }^{30}$

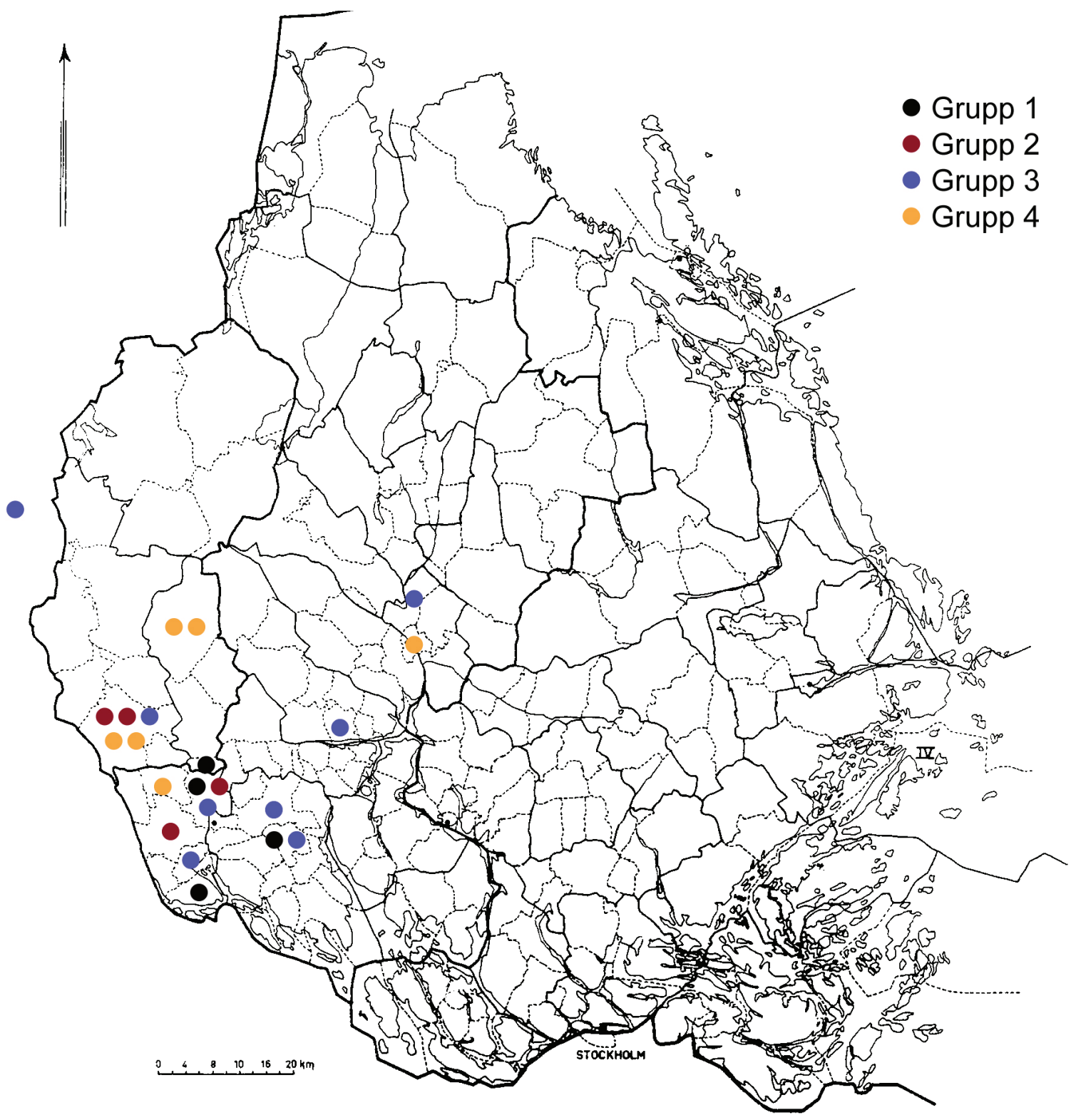

Fig. 6. Spridningen av Eriks ristningar fördelade pă de fyra grupperna. Karta förf.

Utformningen av en del andra element tyder på att denna gruppering av materialet är riktig. U 1165 har t.ex. en speciell form av bandknut med insvängda sidor där det på insidan av knuten lämnas ett litet halvcirkelformat utrymme närmast slingan. Samma typ av bandknut återfinns även på U 768 och U 774, som båda tillhör grupp 1, men förekommer egentligen inte annars. Man kan också notera att de linjer som bildar kor30 Jag har här också gjort ett försök att ordna ristningarna efter likhet även inom grupperna, men den exakta ordningen kan naturligtvis diskuteras i en del fall. Några av stenarna är dessutom försvunna och endast kända genom äldre avbildningar, vilket gör det svårt att bestämma alla detaljer. 
sets smalare fot på dessa tre stenar är helt parallella, medan korset på Eriks övriga stenar i regel har en fot som är bredare nedtill och smalnar av upptill. Det går också att ställa vissa drag i runtexterna mot de nämnda grupperna. Exempelvis förekommer åsrunan (o) endast i grupp 1 och 2, medan utelämnandet av demonstrativt pronomen vid objektet stcein är begränsat till några ristningar i grupp 4.

Om Eriks ristningskonst har genomgått en sådan utveckling som ovan har skisserats finner vi hans äldsta stenar i den västra delen av Fjärdrundaland - i Härnevi, Vårfrukyrka och Enköpings-Näs socknar - medan de yngsta uppträder i utkanterna av hans verksamhetsområde i bl.a. Vittinge och Uppsala (fig. 6). Slående är att det är just i det sistnämnda området som han väljer att utforma rundjurets huvud på ett nytt sätt. Det är också i dessa ytterområden - i Möklinta i väster och Uppsala i öster - som han har valt att arbeta i just röd sandsten.

\section{Referenser}

Androshchuk, Fedir (2014). Viking swords. Swords and social aspects of weaponry in viking age societies. Stockholm: Statens historiska museum.

ATA = Antikvarisk-topografiska arkivet, Riksantikvarieämbetet, Stockholm.

Brate, Erik (1925). Svenska runristare. Stockholm: Kungl. Vitterhets-, historie- och antikvitetsakademien.

Dybeck, Richard (1868). Reseberättelse 1868 (ms. i ATA).

Grau, Olof (1754). Beskrifning öfwer Wästmanland med sina städer, härader och socknar. Västerås.

Gräslund, Anne-Sofie (2006). Dating the Swedish Viking-Age rune stones on stylistic grounds. I: Marie Stoklund et al. (eds.), Runes and their secrets. Studies in runology. Copenhagen: Museum Tusculanum Press. S. 117-39.

Hagenfeldt, Stefan E. \& Palm, Rune (1996). Sandstone runestones. The use of sandstone for erected runestones. Stockholm: Sällskapet Runica et mediævalia.

Quak, Arend (2003). Airikr hiuk. Zu den Inschriften des Runenmeisters Erik, i: Heizmann, Wilhelm \& Nahl, Astrid van (red.) Runica - Germanica - Mediaevalia. Berlin: de Gruyter.

Rannsakn. = Rannsakningar efter antikviteter. 1-4. Red. Stahre, Nils-Gustaf et al. 1960-98. Stockholm: Kungl. Vitterhets-, historie- och antikvitetsakademien.

Raä + nummer = Nummer i Riksantikvarieämbetets fornminnesregister. $<\underline{\text { http://www.raa.se/ }}$ hitta-information/fornsok-fmis/>

$\mathrm{SHM}=$ Statens historiska museum. Inventariekatalogen och inventariehandlingar finns tillgängliga på Internet: < http://mis.historiska.se/mis/sok/sok.asp>

Stille, Per (1999). Runstenar och runristare i det vikingatida Fjädrundaland. En studie i attribuering. Runrön 13. Uppsala.

UR 1-4 = Upplands runinskrifter. Granskade och tolkade av Elias Wessén \& Sven B. F. Jansson. Sveriges runinskrifter 6-9. Stockholm.

Zachrisson, Torun (2013). Gamla Uppsala på nytt. I: Sundqvist, Olof \& Vikstrand, Per (red.) Gamla Uppsala i ny belysning. Uppsala: Swedish Science Press. 